\title{
The Importance of Needs in Uses and Gratification Theory
}

\author{
Faiswal Kasirye \\ Department of Communication, \\ International Islamic University Malaysia
}

\begin{abstract}
Uses and Gratifications Theory
Coined in the early 1940s by Katz and Blumler (1974), the uses and gratifications theory deals with understanding why people use certain types of media, what needs do they have to use them, and what gratifications do they get from using them. Historically, the theory was first introduced to understand why people chose to consume the various forms of media that were present at the time in 1940s.
\end{abstract}

Currently, the theory relies on two assumptions regarding the media. It suggests that, the audiences are active members of the media through the selection of their preferred content that they consume. The second assumption being that the media users or consumers and more aware of the reasons why they choose the particular media that they choose to use or consume. However, the scholars build on those two assumptions and lists other key assumptions including.

- Media influence on behaviour if through psychological factors.

- Media usage is goal oriented.

- A particular media is selected based on its notion that it will satisfy the specific needs and wants of the user.

- The media is always in competition with other communication type; and

- That since people are always in control of the media, therefore it influences them on a huge basis.

However, the theory recognizes that individual have great and huge powers on their decision on what they want in a media over the influence that the media may have on them. Furthermore, the theorists (Katz, Gurevitch \& Haas, 1973) categorized the uses and gratifications theory in some needs which include; affective needs, cognitive needs, personal integrative needs, social integrative needs and as well as tension free needs. However, this write up focuses on 
understanding the importance of these needs in understanding further the uses and gratifications theory and the needs are discussed below.

\section{The importance of needs in uses and gratifications theory}

\section{Cognitive needs}

The first needs in uses and gratifications theory relate to cognitive needs that concern getting knowledge and information as well as having an understanding of people's social environments, exploration and curiosity (Ruggiero, 2000). This need stresses that users choose particular media simply because they are looking for some information and facts because the media is known for publishing facts. For example, there could be a constant television program relating to the history of prophet Muhammad (PBUH), the users looking for information and facts on the prophet then tune in to watch that particular program because it has some gratifications that it is going to give to the viewer or rather the user. However, the current social media that is rampant with fake news might prove otherwise and if one is not careful, they might end up consuming misinformation relating to that very issue.

It should however be acknowledged that people have different needs and wants and why they choose to watch or view the programs that they watch. Different programs might be giving different satisfactions to the views therefore, it might not be easy for two people to be wanting the same things at the same time.

Therefore, it is important to study and understand the uses and gratifications in detail, and later also understand the cognitive needs that are proposed by the they in order to know how it can be applied in attitude and user behaviour studies in future.

\section{Affective needs}

These are appealing experiences and needs that relate to pleasure. In other words, people use different types of media for personal needs like pleasure and or emotional needs like getting satisfaction from a football match aired on television. When someone watches a football match, the most they can get from it is pleasure to your mind and soul. It can happen when the opposite side that they support scores them and then all of a sudden they become sad because of the score. 
So the scoring of the rival team makes them sad to the point of getting emotional should one mock them on the matter.

Understanding how to handle one's self in such emotional situations is very important and also, knowing that this type of need happens in human beings may reduce the person's negative reactions should they encounter it with the knowledge. Therefore, studying it may be of great help to the user and those who are engaged in such activities that give satisfaction to the users of those particular media.

\section{Personal identity/interactive needs}

This particular need is very important to the lives of people because it touches their inner feeling. The need concerns self-esteem, personal stability, need for self-respect, self-confidence, integrity and social status and others in the same category (Stafford et al., 2004). In addition, it connotes that people choose to use the different media platforms to gain credibility and raise their status among their fellows. Being stable is a very important aspect in the society, therefore, people may watch or listen to television to stay connected and important in the society so that he has a place among residents of a society. Another example may be when one buys a very expensive car they saw on television advertisement just to earn respect among his fellows and in the end change the way they live. That's why, usually when respected companies are planning to make adverts, they put much emphasis on celebrities that might influence the viewers to buy products such as the ones that they have seen a celebrity advertising in a television advert, and since the advert is seen by many people on television, his status will be high because he has a very expensive car they bought after looking at the advert and therefore gaining social status from other people.

\section{Social interaction and integration needs}

The needs under social interaction related to interacting with family, friends and relatives but rather with technological integration now days unlike two decades' ego where there were no social media interactions. Now days people decide to use the different media platforms to fulfill their desires of chatting and engaging with their family relations and friendship, the need for affiliation to other people, and also the desire to feel a connection to the outside world from their location. This is common in the current times where even people who are in countries where they are not citizens, 
they may keep receiving information relating to their countries as though they are present there in real time.

In addition, this need might be also important because it attracts people to come together to enjoy a certain program together. This may happen by way of exchanging information on what each one is enjoying while on television or on social media or even on another media website. It could be a new movie and both decide to exchange the access to the media platform and then each one enjoys the program on their own but the central point being that, the second person is enjoying the program not because they have any satisfaction that they are looking from it, but rather because their friends are watching it and so they also decide to watch the same and then the next time they meet, they have a candid discussion about that movie that can combine their talk.

This need is very important to be explored and studied because its relation is on technology and technology keeps on evolving every other day and therefore whenever new technology emerges, new other measures of accessing it may also emerge and hence new needs also have to come up. It is important to know that social media is no days the fastest way of socializing and information flow because you no longer have to meet up with any one even if you wanted to when there are a number of platforms that allow online meetings for as many people as possible. Therefore, studying this type of need in satisfying the users of the media, helps to understand why they choose those particular media platforms what they gain from using them.

\section{Tension release needs (escapism)}

This needs may warrant users to use a certain media because they want to escape a certain unpleasant situation and that they just want to take their minds off the issues that could have been bothering them. It can be a quarrel with a fried, wife, husband or fellow worker, but instead of engaging in the quarrel, you decide to keep your mind on a particular media program to avoid thinking about the issue in question. This is usually done in anticipation that the time one will spend on the particular media program, it will help them calm down and or grab their attention

from what was bothering them and instead decide to concentrate on the media program. It can be a radio program, tv or even chatting or scrolling through a social platform.

In a nutshell, the needs from the uses and gratifications theory are indeed very particular because they touch and address individual users of the media and how the particular media platforms gratify 
their needs and wants because people's needs are different. Therefore, the needs as discussed above are very important to be explored and studied in every aspect of life.

\section{Criticisms of uses and gratifications theory (Elliott,1974)}

Firstly, the authors of the theory (Katz, Gurevitch \& Blumler, 1974) made an assumption that the media users are aware of the needs and the gratifications that they want to get out using them. However, the main critique of the theory lies in the fact that, the assumption of people knowing their needs and gratifications is not certain because it is practically impossible for people to be knowing all their needs and gratifications because some of them come along the way when they are using the media platforms and not thought about before. An example may be, one can decide to watch a certain media program to escape an unpleasant situation that could have annoyed them but altogether at the end of the program, the reaction may fail to change or it could even result into a different need or gratification. This issue is very pertinent and checks the core assumptions of the main theory because they look like they do not have safe burtons.

Secondly, the theory only talks about how users are aware of the reasons and needs why they use the media, but forget to talk about the power of the media. Highlighting the power of the media is crucial because the media is the one that gives power and influences the user to opt for it, otherwise if that particular media chosen by the user did not have good content or attractive content for that matter, chances are that the user would most likely not have chosen it to gratify their needs. Also because te different media platforms particularly social media, offers different options in the way one can communicate and or otherwise use the platform in their own way to make sure that at the end of the program, the program has changed their mindset and become satisfied.

The other criticism that scholars have found out over tie is that the theory is more audience centered than media centered. this is because, all its variables are related to the audience and or the users Rather than assuming anything related to the media yet the users have to use the media in order to gratify their needs. Therefore, more is needed to be done on the part of the media and how it can be incorporated in the excerpts of the theory.

Furthermore, the theory mainly talks about individual's selection of their preferred content to use in the media but it rather forgets the effects it can bring about their minds if they don't look at it in an objective way. The theory in short focuses on the content and media and it neglects to address 
the issue what is on people's minds when they are selecting the particular media that they use in satisfying their needs for its usage.

Lastly, most studies that have used the theory have had to conclude that they always get subjective results rather than those that covers a wider perspective. Part of the problem scales from the fact that the theory only focus on the users and it neglects to consider the media therefore, the subjectivity may apply in that manner.

\section{REFERENCES}

Blumler, J. G., Katz, E., \& Gurevitch, M. (1974). Utilization of mass communication by the individual. The uses of mass communications: Current perspectives on gratifications research, (s 19), 32.

Elliott, P. (1974). Uses and gratifications research: A critique and a sociological alternative. The uses of mass communications: Current perspectives on gratifications research, 3, 249-268.

Katz, E., \& Blumler, J. G. (1974). The uses of mass communications: Current perspectives on gratifications research.

Katz, E., Haas, H., \& Gurevitch, M. (1973). On the use of the mass media for important things. American sociological review, 164-181.

Ruggiero, T. E. (2000). Uses and gratifications theory in the 21 st century. Mass communication \& society, 3(1), 3-37.

Stafford, T. F., Stafford, M. R., \& Schkade, L. L. (2004). Determining uses and gratifications for the Internet. Decision sciences, 35(2), 259-288. 